\title{
1. Introduction: entrepreneurial ecosystems and the diffusion of startups
}

\author{
Sharon Alvarez, Elias G. Carayannis, Giovanni \\ Battista Dagnino and Rosario Faraci
}

\subsection{PURPOSE}

The goal of this book is to contribute to the emerging debate on entrepreneurial ecosystems and the diffusion of startups by providing a set of well-rounded chapters, written by leading scholars from various parts of the world in the field of entrepreneurship and strategy that collectively significantly advance the evolution of the subject in the relevant knowledge domain. We seek to explore new ideas, provoke debate in both academia and practicing business agents, and deliver high-level forward-looking investigation in areas related to these emerging phenomena.

We have gathered nine relevant conceptual and empirical contributions written by 21 authors from the United States and Europe specifically prepared for this endeavor. Taken together, the contributions push forward the porous boundaries of the entrepreneurship field as well as the business conversation and scholarly debate on entrepreneurial ecosystems and startups. In such a way, the book is able to inform academic thinking and offer implications helpful to a range of practitioners such as entrepreneurs, executives, consultants and policy makers.

There are three explicit contributions that the book advances. First, it pulls notable attention and generates substantial awareness on the key issue of entrepreneurial ecosystems design, establishment, organization and evolution. Second, it advances an organized synopsis of the extant literature on entrepreneurial ecosystems to dissect the advances made and the current status of ecosystems research. Third, it portrays a highly valued selection of examples of entrepreneurial ecosystems at work and discusses their implications for entrepreneurial theory and practice. Amongst these examples, the volume illustrates the emergence and impact of AppCampus (a project aimed at leveraging and enhancing the entrepreneurial ecosystem generated 
by Aalto University and the Windows Phone innovation ecosystem), the main features of UK fashion design micro enterprises, the incubator perimeter mapping methodology, understanding of how social capital affects the funding of products in various industry projects that are crowdfunded by means of Kickstarter online platform and the reasons for knowledge spillover and agglomeration of new ventures in innovation-intensive regions.

\subsection{ROOTS}

The book is based on a thorough selection of the best works presented on the occasion of a milestone meeting, entitled "Entrepreneurial Ecosystems and the Diffusion of Startups", held at the University of Catania, Italy, on 23-25 May 2013 (see cataniaentrepreneurship2013.wordpress.com/) that was expressly aimed to produce this book. Gathering under the same roof, over 60 interested participants came together from three continents (Europe, America and Asia) and 11 different countries. The meeting was cosponsored by the Academy of Management's Entrepreneurship Division, and the Department of Economics and Business of the University of Catania. It is worth noting that participants had the opportunity to attend the inaugural session in the premises of JoYà Academy, an idea creation lab in the fashion industry, which is located in a particularly intriguing space with a black tuff volcanic stone atmosphere, imaginative illumination, and artistic installations that, many years ago, hosted the warehouses of the sulphur refinery workshops of Catania. Far from being an intrusive one, the condition of being a collective endeavor has allowed us to strengthen the thematic element of the book, as well as to pursue internal coherence and overall consistency of the volume.

\subsection{MOTIVATION}

Interest in the key theme "Entrepreneurial Ecosystems and the Diffusion of Startups" is spreading from the rapidly increasing role that entrepreneurial ecosystems and startups are assuming in today's business world. From a remote corner of the study of entrepreneurship and strategy, it has now taken center stage in the field of entrepreneurship. The study of entrepreneurial ecosystems has recently met with unexpected success by attracting a wide-ranging selection of novel contributions:

(a) Research reports and executive summaries by various well-respected institutions, such as the Kaufmann Foundation's report on measuring 
an entrepreneurial ecosystem (Stangler and Bell-Masterson, 2015), by the Organisation for Economic Co-operation and Development (OECD) (Mason and Brown, 2014) and from Startup Genome and Telefónica Digital (2012) on mapping startup ecosystems.

(b) Case studies for MBA and executive education courses, such as the recent Harvard Business School case, Rising from the Ashes: The Emergence of Chicago's Entrepreneurial Ecosystem by Linda Applegate and associates (2017).

(c) Book chapters (Cinici and Baglieri, 2016; Minà et al., 2016) and books, such as Entrepreneurial Ecosystems (Boutillier et al., 2016), focused on the role of entrepreneurial ecosystems on economic growth, as well as the well-circulated Startup Nation (Singer and Senor, 2011) and the present volume.

(d) Call for papers for special issues of academic journals, such as Small Business Economics: An International Journal (Colombo et al., 2015) and Strategic Entrepreneurship Journal (Autio et al., 2015).

(e) A few initial articles of premier academic journals dedicated to entrepreneurship and the issue of entrepreneurial evolution (Spigel, 2017).

In a broad sense, an entrepreneurial ecosystem considers the actors and the environment affecting the rise and diffusion of entrepreneurship at the "glocal" level. It encompasses a group of firms, including startups, and one or more coordinating entities, such as firm incubators or accelerators and local policy agencies, which share similar goals and decide to form a network to leverage scale economies, as well as entrepreneurial flexibility and a strong drive to innovate (see Isenberg, 2014; Financial Times Lexicon, 2017). Alongside the recent outburst of entrepreneurship at the glocal level, the rise of new startups and startup ecosystems around the world, as well as new-found developments in existing ones, has picked up. For instance, the Startup Ecosystem Report 2012 (Startup Genome and Telefónica Digital) argues that countries and cities are shifting from service-based economies to becoming increasingly driven by a new generation of fast-moving software and technology-rooted business organizations. Interestingly, the OECD in November 2013 organized a meeting on entrepreneurial ecosystems (Mason and Brown, 2014), underscoring that the burgeoning issue has far-reaching implications, involving economic development, planning, economic geography and policy perspectives. To be sure, with entrepreneurial ecosystems we do not limit the inquiry to spatially bounded intra-industry or inter-industry contexts, but extend our reach to virtual entrepreneurial ecosystems that are global in nature.

Therefore, while we recognize that the spatial dimension may be relevant 
to entrepreneurial ecosystems that are located and concentrated in certain regions (Silicon Valley, Israel, Ireland and Taiwan), and in these cases regional conditions are rather important, we concurrently posit that the spatial dimension may today be increasingly superseded by "glocal" and virtual forces given by global drivers of entrepreneurial platforms. We also acknowledge that entrepreneurial ecosystems are inherent drivers of innovation and new business energy and power. Successful startup ecosystems usually foster a long-term view, process-structure recombination across boundaries, and entrepreneurial dynamics to shore up communities of entrepreneurs and investors who share the aspiration to cultivate each other's talent, creativity and network support as shown in the case of Chicago (Applegate et al., 2017).

On the other hand, weak entrepreneurial ecosystems may display a range of key weaknesses that need to be tackled, such as the need for venture capital money to finance growth, the need for enlarged and more intense valuable networking as well as ways to attract skills and talents to speed up growth, and the need for a major coordination role by universities and research centers. In addition, what is also necessary is the presence of change agents and orchestrators that are effectively able to perform as role models and champions of entrepreneurial ecosystems. This is the case in the Scottish entrepreneurial ecosystem as represented by Levie and associates (2014). Finally, entrepreneurial ecosystems are loci or relevant settings where the actual co-existence and operational interplay of the two countervailing centripetal and centrifugal forces of competition and cooperation may actually occur taking the form of actor coopetition (Minà et al., 2016). This condition happened in a Canadian hi-tech entrepreneurial ecosystem located in the Quebec region.

\subsection{AUDIENCE}

As indicated above, this book is aimed at both academics and practitioners. On the one hand, researchers, scholars and graduate students of entrepreneurship and strategic management and related topics will be certainly interested in a book that tries to address, for the very first time, in a systematic fashion the notion of entrepreneurial ecosystems as well as delving into entrepreneurial ecosystems emergence, dynamics and management. On the other hand, practitioners, managers and consultants will find in the book conceptual tools and a wealth of practical examples, besides some intriguing experimental evidence, that will trigger innovative ways of thinking about and building ecosystem and startup strategies.

Accordingly, since the book provides in-depth examples, hints, princi- 
ples and techniques about entrepreneurial ecosystems, it might help a fair number of individuals to recognize and assess the imperative needed to take into account when considering the ecosystem option, both in a local and virtual fashion, in today's business world.

The book is mainly for a graduate and postgraduate student audience. Nonetheless, it may provide particularly significant reading for advanced undergraduate courses and seminars. As mentioned previously, given its pioneering and original flavor the book can be a main text for a range of newly designed and launched courses on ecosystems and startup strategies that seem of remarkable appeal or even increasingly required by a range of audiences today. In addition, it may be supplementary or complementary reading to a range of academic and non-academic or post-experience courses (both basic and advanced) in "entrepreneurship", as well as in "strategic management".

As the book's writing style is easily accessible to various kinds of readership, the book may be used in MBA courses and in other graduate and postgraduate courses on entrepreneurial ecosystem and startup strategies since, as indicated, it seems particularly well suited for newly developed courses in these areas. In addition, since it is unlocking an entirely new entrepreneurship subfield, the book can also be a fertile base for running executive education initiatives.

Finally, since it offers an array of intriguing practical implications, we envision that the book will be particularly appealing to a range of practitioners, such as entrepreneurs, executives, consultants and policy makers.

\subsection{STRUCTURE OF THE BOOK}

The volume features nine chapters dedicated to the study of entrepreneurial ecosystems and the diffusion of startups: this introduction, seven core chapters and a concluding chapter. All the chapters are original in nature since they have been specifically written by their authors for this editorial effort. The book's structure essentially responds to the criterion of easy reader comprehension and accessibility. The chapters follow a rational order beginning with an overview of the literature to in-depth analysis of intriguing cases of entrepreneurial ecosystems that are industry-specific, city-specific or region-specific, to the effective design of an entrepreneurial ecosystem and discussion of a methodology to assess the latitude of a startup incubator.

Chapter 2 by Anna Minà and Giovanni Battista Dagnino is entitled "Mapping entrepreneurial ecosystems inquiry: a content analysis of the analysis of the literature and its implications". The chapter underscores 
that awareness of the business ecosystem and the intellectual ferment it has generated, especially in the last decade, motivate the need to develop a systematic overview of the existing literature on ecosystems. The authors develop a content analysis of existing studies on ecosystems to grasp the main features and key elements that epitomize an ecosystem and then to untangle the boundary conditions around which firms can extend their entrepreneurial visions matched with strategic thinking within the ecosystem.

Chapter 3 by Llewellyn Thomas, Dmitry Sharapov and Erkko Autio is entitled "Linking entrepreneurial and innovation ecosystems: the case of AppCampus". It contributes to recent work examining entrepreneurs who participate in multiple ecosystems simultaneously by investigating the mechanisms and outcomes of the AppCampus initiative, a three-year project aimed at leveraging and enhancing the entrepreneurial ecosystem around Aalto University and the Windows Phone innovation ecosystem. The chapter reviews the characteristics of innovation and entrepreneurial ecosystems, and provides an analysis of the Windows Phone ecosystem and the Aalto entrepreneurial ecosystem. It illustrates the AppCampus initiative, clarifying each of its components and how these are linked to the Windows Phone innovation and Aalto University entrepreneurial ecosystems. The authors then discuss the effects that AppCampus has had on these ecosystems and future directions for leaders of entrepreneurial and innovation ecosystems.

Chapter 4 by Nicolai Foss and Jacob Lyngsie is entitled "Antecedents of firm-level entrepreneurship: how organizational design coordinates and controls the firm's entrepreneurial ecosystem". In this chapter, the authors propose a framework to understand how organizational design fosters those behaviors that aggregate firm-level entrepreneurial outcomes in an entrepreneurial ecosystem (that is, engaging in new markets, securing new sources of inputs, and realizing organizational, process and product innovations). The proposed framework links organizational design, intra-firm entrepreneurial behaviors and firm-level entrepreneurship. This responds to the requisite to fill a specific research gap in the literature: in fact, the entrepreneurship literature has tended to ascribe entrepreneurial capacity and outcomes either to individuals that start up new ventures or have located such capacity and outcomes at the level of firms.

Chapter 5 by Vincenzo Butticè and Massimo G. Colombo is entitled "Industry specificity and the effect of internal social capital in rewardbased crowdfunding". The chapter shows that while the crowdfunding literature has highlighted the role of social capital developed within the platform (internal social capital) in determining the success of a funding campaign, prior studies have failed to emphasize that industry specificity 
may influence this effect. The chapter fills this gap by dissecting how social capital influences the funding of products belonging to different industries. Using a dataset of 34,121 projects launched on the Kickstarter online platform during the year 2014, the authors found that the internal social capital effect varies by industries and is stronger in magnitude when the industry is characterized by high demand uncertainty and task complexity. Overall, these findings contribute to a better understanding of the role of social capital in the phase known in venture capital studies as early stage financing.

Chapter 6 by Alison Rieple, Jonathan Gander, Paola Pisano, Adrian Haberberg and Emily Longstaff is entitled "Accessing the creative ecosystem: evidence from UK fashion design micro enterprises". The chapter examines the impact of the UK fashion design micro enterprises ecosystem on the practices of fashion designers. This ecosystem includes what is termed a socially "sympathetic infrastructure" (Pratt, 2002) and nodes: a mix of social spaces, meeting points, public areas such as markets and streets, as well as sources of inspiration such as museums and art galleries. The authors scrutinize the extent to which creative micro enterprises, such as fashion designers, access external resources to compensate for their putative internal deficiencies. In doing so, they build on a typology of apparel designers and test whether its combination of market and peer-based orientations explains the behavior of their sample. They also detect resource nodes: physical sites where actors in a design ecosystem may encounter one another and the material objects that are there, exchange ideas, give and receive emotional support and arrive at a shared understanding of design memes. Finally, the authors investigate the role of creative micro enterprises in the transmission of symbolic knowledge and the negotiation of shared meanings, and how different types of designers may use these in various ways.

Chapter 7 by Emanuele Parisi, Angelo Miglietta and Dario Peirone is entitled "Business incubators and entrepreneurial networks: a methodology for assessing incubator effectiveness and performance". The chapter maps the incubator's perimeter, underscoring the role of connector and activation centers of entrepreneurial ecosystems, thereby setting the theoretical framework for a model of incubator assessment whereby success drivers are derived from global best practices. This framework aggregates and harmonizes the effectiveness of incubation activities in given perimeters, thereby helping investors to better allocate private and public resources, and offers insights to government that may be useful in addressing national public policies.

Chapter 8 by Elias Carayannis and Mike Provance is entitled "Towards 'skarse' entrepreneurial ecosystems: using agent-based simulation of 
entrepreneurship to reveal what makes regions tick". The chapter starts by formulating and simulating the life cycle of knowledge-driven ventures that can be viewed as the exercise of real options under regimes of risk and uncertainty that are modeled in the form of "happy accidents", namely, strategic knowledge serendipity, arbitrage and acquisition events that punctuate the process of the venture's life cycle. The authors found that the timing, selection and sequencing of key decisions regarding new venture formation and evolution are contingent in a non-linear manner on the breadth and depth as well as the quality and density of the network structure of the business and technology ecosystem within which a venture is situated. Up to a certain point of cultivating and nurturing the new firm's socio-economic network, the costs outweigh the benefits, but with an abrupt about-face once a critical mass in the scale, scope and quality of this socio-economic network or business and technology ecosystem is attained, the benefits start outweighing and exponentially exceeding the costs. The implications for technology entrepreneurs, regional economic development managers and policy makers are apparent: fathom the nature and dynamics of their own regional business and technology ecosystem and aim to enter the market (as an entrepreneur) when the ecosystem appears to be close to its critical mass of maximum likelihood knowledge serendipity and arbitrage ("happy accidents") events, as well as aim to help the ecosystem reach its maximum "happy accident" likelihood state as sustainably and fast as possible and become in this manner a skarseenabled entrepreneurial ecosystem (Carayannis, 2008). In this context, strategic public-private partnerships and networks, as well as risk capital, serve as key pillars of sustainable and accelerated economic development. Through the use of a simulation, the chapter supports arguments regarding localized spillover of knowledge and agglomeration of new ventures within innovation-intensive regions, but only after new ventures have acted independently to create formal networks that acquired knowledge from more distant regions. Further analysis demonstrates the substantial influence that institutions have on the formation of new ventures. Institutions that increase the diversity of knowledge flows make positive impacts on the survival of new ventures and the sustainability of entrepreneurship in a region, while heterogeneity-reducing institutions (such as ones that replicate existing knowledge or produce standardized knowledge) impede the progress of new venture formation at firm and regional levels.

Finally, the concluding chapter focuses on a few key conditions epitomizing a healthy entrepreneurial ecosystem. Drawing on a complex adaptive system approach to entrepreneurial ecosystems evolution, we call for a dynamic approach to entrepreneurial ecosystems to grasp how they emerge, maintain vitality, and deteriorate. This condition may proffer 
helpful groundwork to develop a value-based theory of entrepreneurial ecosystems that may allow us to understand entrepreneurial ecosystems evolutionary paths and governance systems and mechanisms.

\section{REFERENCES}

Applegate, L., Meyer, A., and Varley, T. (2017). Rising from the Ashes: The Emergence of Chicago's Entrepreneurial Ecosystem. Harvard Business School Case 9-817-061.

Autio, E., Nambisan, S., Wright, M., and Thomas, L.D.W. (2015). Entrepreneurial ecosystems. Strategic Entrepreneurship Journal. Special Issue Call for Papers. Available at: onlinelibrary.wiley.com/store/10.1002/(ISSN)1932-443X/asset/hom epages/SEJ-Entrepreneurial_Ecosystems.pdf?v=1\&s=4548d7b62c28292b826ef7 d74eae7bfcd396f34a\&isAguDoi=false.

Boutillier, S., Carré, D., and Levratto, N. (2016). Entrepreneurial Ecosystems. Hoboken, NJ: Wiley.

Carayannis, E.G. (2008). Knowledge-driven creative destruction, or leveraging knowledge for competitive advantage. Industry and Higher Education, 22(6).

Cinici, M.C. and Baglieri, D. (2016). (Not) energizing ecosystems through a large firm's inventor network: lessons from Italy. In H. Wang and Y. Liu (eds), Entrepreneurship and Talent Management from a Global Perspective. Cheltenham, UK and Northampton, MA, USA: Edward Elgar Publishing, pp. 227-50.

Colombo, M., Dagnino, G.B., Lehman, E., and Salmador, M. (2015). The governance of entrepreneurial ecosystems. Small Business Economics: An Entrepreneurship Journal. Special Issue Call for Papers.

Financial Times Lexicon (2017). Definition of entrepreneurial ecosystem. Available at: lexicon.ft.com/Term?term=entrepreneurial\%20ecosystem. Accessed 29 April 2017.

Isenberg, D. (2014). What an entrepreneurship ecosystem actually is. Harvard Business Review online. Available at: hbr.org/2014/05/what-an-entrepreneurialecosystem-actually-is. Accessed 5 May 2017.

Levie, J., Autio, E., Reeves, C. et al. (2014). Assessing regional innovative entrepreneurship ecosystems with the global entrepreneurship and development index: the case of Scotland. Available at: https://www.enterpriseresearch.ac.uk/ wp-content/uploads/2014/03/REAPScotlandGEMconfV13-Autio.pdf.

Mason, C. and Brown, R. (2014). Entrepreneurial ecosystems and growth oriented entrepreneurship. OECD, Paris. Available at: http://www.oecd.org/cfe/leed/Entre preneurial-ecosystems.pdf. Accessed 4 May 2017.

Minà, A., Dagnino, G.B., and Ben-Letaifa, S. (2016). Competition and cooperation in entrepreneurial ecosystems: a life-cycle analysis of a Canadian ICT ecosystem. In F. Belussi and L. Orsi (eds), Innovation, Alliances and Networks in High-tech Environments. Abingdon, UK: Routledge, pp. 65-81.

Pratt, A. (2002). Hot jobs in cool places. The material cultures of new media product spaces: the case of south of the market, San Francisco. Information, Communication and Society, 5(1), 27-50.

Senor, D. and Singer, S. (2011). Start-up Nation: The Story of Israel's Economic Miracle. New York: Twelve. 
Spigel, B. (2017). The relational organization of entrepreneurial ecosystems. Entrepreneurship Theory and Practice, 41(1), 49-72.

Stangler, D. and Bell-Masterson, J. (2015). Measuring an Entrepreneurial Ecosystem. Kaufmann Foundation. Available at: http://www.kauffman.org/ / media/kauffman_org/research\%20reports\%20and\%20covers/2015/03/measuring _an_entrepreneurial_ecosystem.pdf.

Startup Genome and Telefónica Digital (2012). Startup Ecosystem Report 2012. Available at: http:// www.clustermapping.us/resource/startup-ecosystem-report2012. Accessed 5 May 2017. 